\title{
A Critical Examination of Disability and Agency through Art
}

\section{Réflection critique sur le handicap et l'autonomie qu'apporte l'art}

\author{
Theodore Albano ${ }^{1}$ \\ ${ }^{1}$ Arteïa: UK Managing Assistant, The Art Identification Standard Consortium: Membership Coordinator, 2019 MLitt. \\ Film, Visual Culture and Arts Management, The University of Aberdeen, 2014 B.A Art History, The University of British \\ Columbia
}

ABSTRACT. Throughout history and the historical canons of western art, disability and the afflicted human form have often been marginalized and used as manifestations of iniquity, social malfeasance and mental degradation. It is not until the $20^{\text {th }}$ and $21^{\text {st }}$ centuries that changing social attitudes, as well as rapidly transforming scientific and medical advancements have reshaped how disability is framed, shown and discussed. In this article the author delves into the artistic, medical, scientific, and social complexities surrounding this topic to shed light on its multipart, shifting narratives.

KEYWORDS. Prosthetics, disability, agency, Capua Leg, Otto Dix, Pieter Breughel, The Card Players, The Cripples, Metropolis, Konrad Biesalski, Francis Derwent Wood, Rosi Braidotti, Vivian Sobchak, Janine Thewatt-Bates, Raoul Hausmann, Sophie de Oliveira Barata, Posthumanism, Fritz Lang, Sola Fide, New Objectivity, Neue Sachlichkeit, Dada, Protestant Reformation.

One of the great inevitabilities of the human condition is the inherent frailty of our corporeal body, concomitant with the irony of our obsession with immortality and the super body. The great equalizer of all humanity can be essentialized to the sobering fact that one day our human form will crumble. No human is impervious to the ravages of age, disease or affliction. Almost one billion people today, or roughly fifteen percent of the world's population, live with a disability, whether it be mental or physical. ${ }^{1}$ Throughout history we as people have developed to co-exist with these realities. Disability and the use of prosthetics stretches back many millennia, and both have been present in art and practical application; however, people with disabilities have been represented in art more often as "visual and cultural objects" ${ }^{2}$ rather than active participants in their own selfdefinition. Throughout all the historical examples we see disability used as a symbol of moral corruption, of social corruption, or as a political tool. It is only now in contemporary $20^{\text {th }}$ and $21^{\text {st }}$ century society that we are trying to move beyond this in order to highlight the individual as someone not defined solely by the disability. With an historical examination of this subject, particularly of the late medieval and post-World War One periods, as well as contemporary writings by civilians Rosi Braidotti, Vivian Sobchak, Janine Thewatt-Bates and interviews with a war veteran amputee and a contemporary artist working with prostheses' designs, we can see how attitudes surrounding disability in art and culture have changed in a positive and transformative way. Today we are entering an age of greater understanding about prosthetics and technology, and greater agency is now given to the disabled, which frames and changes our understanding of humanity as a whole.

${ }^{1}$ Martin, E, Disability Studies in Art History, 2018

${ }^{2}$ Martin, 2018 
Currently the earliest known and dated prosthetic is a c. 2000 B.C wooden toe found on a mummy in Luxor, just recently in $2009 .{ }^{3}$ There are many mentions of prostheses in ancient texts, including Pliny and Herodotus, as well as additional transformative discoveries such as the famed "Capua Leg"4 dated to approximately 300 B.C., which is thought to be one of the earliest fully functional leg prosthetics. It is not until the medieval period and late medieval period, specifically, that images of prosthetics and physical disability become more prominent, with heavy underlying social, ethnographical and religious subtexts.

The works of the renowned $16^{\text {th }}$ century Flemish artist Pieter Breughel are perhaps some of the best to explore these intertwined relations, specifically his 1568 painting alternately known as The Beggars or The Cripples. ${ }^{5}$

To understand the implications of this piece it is important to have a grasp of the quickly changing ideologies in Northern Europe during this time. The Protestant Reformation was in full sway, and its disavowment and rejection of public religious imagery had shifted many artists towards the philosophy of humanism and reason and an advancement into empirical science.

In earlier medieval and Catholic thought, the disabled and the blind were considered as physical manifestations of the necessity for charitable works of mercy such as the giving of food and alms. These good works, tied with faith, helped to ensure the salvation of the giver. Prior to the late medieval period, depictions of those with physical disabilities are shown almost exclusively in the context of a saint performing miracles to heal them or a saintly figure doling out alms. Perhaps the only exception to this are some small marginalia images of men with crutches in illuminated manuscripts, though even these while nominally secular are still in the context of a religious book. The Protestant doctrine of sola fide, popularized in Northern Europe by Martin Luther in the 1520s, rejected the idea of good works acting as the key to eternal glory, arguing (somewhat callously) that faith alone was necessary. ${ }^{6}$ It was during this period that charity, and the status of charity, for the infirm saw a downturn and beggars saw their lot in life begin to descend even further.

During the $12^{\text {th }}$ century, the Church administered a 10 percent tax on Europe's total annual production (known as the tithe) to the help of the poor and disabled. ${ }^{7}$ By Breugel's time, about 20 percent of the total population of late medieval Europe was destitute or homeless. ${ }^{8}$ This vast rise of destitute individuals was created by constant war and shifting economic opportunity, and they roamed the roads of Europe looking for work or charity. Often these beggars found themselves in three categories: the mentally infirm, the halt and aged, or the deformed and physically incompetent. As the population grew, so did the number of these displaced and vulnerable individuals. As moral and religious ideologies shifted, the infirm became targets of ridicule and symbols of foolishness and depravity. The physical deformities were felt to represent an inwardly present moral decrepitude. ${ }^{9}$

\footnotetext{
${ }^{3}$ Figure 1

${ }^{4}$ Figure 2

${ }^{5}$ Figure 3

${ }^{6}$ Stainton, T., Reason's other: the emergence of the disabled subject in the Northern renaissance, 2004

${ }^{7}$ Hernigou, P., Crutch Art Painting in the Middle Ages as Orthopaedic Heritage 2014

${ }^{8}$ Hernigou, 2014

${ }^{9}$ Stainton, 2004
} 
While the formerly Catholic view of the disabled was by no means perfect, objectifying these figures as mere symbols of charity and disassociating them from their personal identity, the more secular Protestant vision was more complex. In a cruelly ironic way, the figures themselves became more personalized in their depiction of affliction, while they were now branded with the decidedly more sinister label of inherent deviancy.

The painting The Cripples, to our knowledge, is the smallest ever completed by Breughel measuring at only 7.5 " by 8.5 ", yet stands as one of his most engrossing and enigmatic. We see a ring of five figures in an ouroborean cluster, reeling and writhing with sunken eyes and mouths agape. Each figure wears a crudely constructed hat, which suggest imitations of a burgher, a bishop, a peasant, a soldier and a king. ${ }^{10}$ The figures sport prosthetics and wooden legs common at the time: crutches, bent knee-pegs, and handheld pole legs. Each man also wears attached to him a fox tail, which was a symbol of the leper. ${ }^{11}$ Historians have proposed that the group represents members of a procession of lepers from the traditional Twelfth Night Carnival procession, one which was created as a tradition that mocks the folly of man. Perhaps most enigmatic is the cloaked female figure to the right. She appears to be a nun withdrawing from the group, while holding a large empty food bowl. The cripples appear to have been worked into a frenzy by their feeding. Perhaps this is meant as a metaphor representing the vanity and uselessness of feeding and providing alms to a group of untouchables. This notion of disability was increasingly associated with moral defects, and the study of physical abnormality as indicators of character was a pseudo-science so popular that even contemporary, so called enlightened figures such as Erasmus espoused it. ${ }^{12}$

This thematic connection between physical disability and moral turpitude after taking hold in the late medieval period would go on to be the fundamental association with the physically disabled until arguably the second half of the 20th century. Take for example this quote from the 1888 screed On the Scientific Propagation of the Human Race by Victorian eugenicist Victoria Woodhull Martin:

Thou shalt not marry when malformed or diseased

Thou shalt not produce His image in ignorance

Thou shalt not defile His Temple. ${ }^{13}$

This biblically structured quote, harshly defines the "uncleanness" and moral decrepitude associated with disability.

Before arriving at a $21^{\text {st }}$ century discussion of theory and contemporary viewpoints related to disability and body modification in art and society, one more historical period cries for attention. At no time in world history has the prevalence of prosthetics and disability been more present in art, culture and society than that of post-World War One Europe. The writing of this period is also unarguably the genesis for the modern understanding of a combined nature of man and machine, "posthumanity" and an automated world. The horror, destruction and dehumanization of the First World War, aided in no small part by the advancement of modern machinery, caused mankind to

\footnotetext{
${ }^{10}$ Stainton, 2004

${ }^{11}$ Stainton, 2004

${ }^{12}$ Stainton, 2004

${ }^{13}$ Andree, C., Reproducing Disability and Degeneration in the Victorian Fin de siècle, 2016, p.236
} 
confront itself with difficult and often unanswerable questions regarding its place in the world and technology's seat in that world. Millions were killed, and millions more were physically maimed, mentally unhinged or displaced by the vortex of calamity which swept much of the globe in the second decade of the $20^{\text {th }}$ century. Yet, in the ironic happenstance that seems to follow all great conflict, this war also opened up and advanced tremendous knowledge and complexity regarding medical technology and machine invention. Great advancements were made in orthopedics, reconstructive surgery, vaccine use, X-Ray technology, anti-bacterial treatment and hospital organization. $^{14}$

It is the post-World War One milieu of Germany that provides the most fertile ground for an understanding of the changing dynamics and attitudes which originated in the earlier discussed period and morphed into today's contemporary attitudes. While the presence of "crippled beggars" on the streets recalled the aforementioned figures in Bruegel, many other disabled people received competent and even compassionate medical care, rehabilitation for work and education in regular schools so as to become as self-supporting as possible. ${ }^{15}$ In Germany 2.7 million soldiers returned home with permanent disabilities. ${ }^{16}$ This massive influx of people could not be ignored, and both the soldiers themselves and exhibitions about them brought their plight to the general public. An exhibition entitled "The Wartime Care of the Sick and Wounded Soldiers" at the Reichstag in Berlin drew over 100,000 visitors in the winter of $1914 .^{17}$

Dusseldorf based orthopedic doctor and teacher Konrad Biesalski became a critical figure in helping to change general social awareness around disability. In 1915 he published his seminal work "War Cripple Care. An enlightened word for comfort and a reminder" (Kriegskrüppelfürsorge: Ein Aufklärungswort zum Troste und zur Hahnung). This important document sought to normalize and develop compassion for disabled individuals in the German Republic. The text was widely published and included 85 images that depicted the normalization of disability: such as this image of a man with no hands with complex prosthetics working in a factory. ${ }^{18}$ These images were often reprinted in newspapers and magazines and acted as an important part of the changing visual narrative that demonstrated the modern accomplishments of prosthetic technology.

Biesalski would later petition the German government successfully to institute the "Prussian Law on Cripples' Welfare" which was the first German law to guarantee medical treatment, education and vocational training to young people with physical disabilities. ${ }^{19}$ This law was adopted in different forms in many other countries across Europe and was an important step to disability law today. Biesalski described the law's purpose:

\footnotetext{
${ }^{14}$ Clarke, O., Medical advances from horrors of war, 2014

${ }^{15}$ Heynen, Degeneration and Revolution,_2015

${ }^{16}$ Heynen, 2015

${ }^{17}$ Heynen,2015

${ }^{18}$ Figure 4

${ }^{19}$ Heynen, 2015
} 
No one in Prussia should become cripple if this can be avoided. No cripple who can be healed or improved should have to do without the possibility of healing or improvement. No cripple should have to live in the future without love, care and attention. ${ }^{20}$

We can see this unprecedented law that promoted independence, self-reliance and acceptance by others as one of the progenitors of modern disability thought, law and discourse. ${ }^{21}$ This advancement in legal definition allowed the disabled to gain a greater control of their own narrative and independence. It is important to differentiate this attitude from those held by the Catholics and later the Protestants during the pre and post Reformation period. The law promoted by Biesalski is one that seeks to promote social democratization in a secular manner, i.e., charity for the good of all people and society as opposed to religious charity that sought to elevate the individual giver in regard to Catholicism and the cynical pragmatism of Sola Fide held by the Protestants. This idea of social democratization is the key element that would go on to develop into contemporary discourse.

This was not met without criticism, however; Dadaist writer Raoul Hausmann wrote a scathingly satirical journal article entitled The Prosthetic Economy: Thoughts of a Kapp Officer. Here Hausmann's fictional narrator blusters about the importance of Germany needing workers with prostheses because the artificial limbs will never tire. Man would now be able to work twenty-four hours a day. Technology was now producing the perfect worker. Hausmann, moreover, had a point: In 1919, the German Institute of Psychotechnics had advocated redesigning industrial machinery in order to fit prosthetic limbs better and had claimed that factories might actually become more efficient by integrating technologically enhanced workers' bodies into the production line. ${ }^{22}$.

It was in this period that the idea of the melding of man and machine was drawn to the forefront of people's minds, many perceived the social trend toward the functionalizing of the body in the service of industry, perhaps most notably in Fritz Lang's scathingly critical 1927 film Metropolis, ${ }^{23}$ which presented one of the enduring robotic machine/man figures that is still recognizable to us today. This theme was repeated often in visual art, most notably in Otto Dix's 1920 painting The Card Players $^{24}$. The three men are hideously deformed, all sporting impossibly complex prosthetics, with metal jaws, long tubular hearing devices and articulated hand prosthetics. Their metal legs mix with the legs of the table, and it is impossible to tell where the men end and the table begins. The Iron Cross seen on the man at the right is an ironic gesture that implicates the wounded men in their own disability. Despite his horrendous wounds, the man still finds a disturbing pride in the army and in the war that disfigured him.

Interestingly enough, the depiction of disability in much of the art of the period sought in many ways to undermine the precedent that was being set by sympathetic public opinion and law. The veteran with prosthetics and crutches became an iconic figure in this new period of art, in very different ways than the noble figure heralded by Biesalski. Neue Sachlichkeit, or "New Objectivity" as it is known in English, became a prominent mode of expression of artists of the period. This style sought to move away from the idealistic notions of the Expressionism of the earlier period and desired a return to unsentimental reality and a focus on the objective world. Often incorporating

\footnotetext{
${ }^{20}$ Heynen, 2015

${ }^{21}$ Heynen, 2015

${ }^{22}$ Heynen, 2015

${ }^{23}$ Figure 5

${ }^{24}$ Figure 6
} 
aspects of Dada, the New Objectivists, including Otto Dix, Max Beckmann, George Grosz and others, mercilessly lampooned and satirized public opinion and governmental practice.

Although the majority of disabled veterans were provided for by the state ${ }^{25}$, the New Objectivists often chose to depict veteran amputees as beggars (almost in the manner of Brueghel and Bosch), and relegated to the lowest social status. This was done in order to attack the militaristic system that had created such pain and misery, but also to remind the public that even though the government was providing, there was still disdain for the unfortunate and for the militaristic and ruthlessly capitalistic government that had created them. ${ }^{26}$ By putting the disabled on the same sociological plane as those figures seen in Brueghel's work, the New Objectivists sought to cut through what they found to be the disingenuous veneer of empowerment organized by the government through their social programs and work programs.

The work of Otto Dix encapsulated the complex ideology surrounding the disabled during this period perhaps more effectively than any other artist, an exceptional example being the 1928 triptych Großstadt (Metropolis) ${ }^{27}$. The central panel depicts the debauchery of the "Roaring Twenties" in grotesque irony, with a group of scantily dressed women dancing with men to the music of a jazz band. This scene is ironically juxtaposed with its two side panels, depicting amputated war veterans and prostitutes. In the right hand panel, we see expensive prostitutes marching past a grand theatre display and visibly ignoring a war amputee sitting on the ground, who displays the stumps of his amputated legs and wears a small black patch over the missing portions of his face. He holds a hat and begs for alms. Depicted as an outcast because of his disability he looks down at the ground in shame rather than at the nude women. The left hand panel acts in direct contrast, showing a morbid cobblestone street under a railway trestle. Cheap prostitutes point out the way to a brothel while an incapacitated drunk lies comatose in the street. Above the drunk is another amputee; unlike the other cripple in the right panel he is fitted with crude prosthetics and supports himself with a crutch. Also unlike the man in the right panel, he stares unashamedly and intently at the prostitutes and his surroundings.

There is a duality of meaning in this painting. On one hand the disabled veterans are victims, excluded from the erotic and materialistic world around them. ${ }^{28} \mathrm{~A}$ key detail however shows another side: the cripple in the left hand panel is painted as a self-portrait of Dix, who himself was a combat veteran of the First War, and his gaze extends across the entire triptych. This identification with the disabled puts the veteran's perspective as the main perspective in the whole piece, validating his existence and perseverance in the face of an indifferent environment. His disability at once excludes him from the world around him while simultaneously enabling him to see beneath the surface of current reality.

The advancements of the post-World War One period also led to some transformative synthesis of art and technology to create empowering pieces of prosthetics which aimed to give individuality and dignity to the disabled and whose positivist themes would be echoed later in the $20^{\text {th }}$ century and today's contemporary period. The work of Sculptor Francis Derwent Wood is critical to examine as a progenitor of the work of contemporary artist Sophie de Oliveira Barata, discussed

\footnotetext{
${ }^{25}$ Heynen, 2015

${ }^{26}$ Heynen

${ }^{27}$ Figure 7

${ }^{28}$ Heynen, 2015
} 
later. Derwent Wood created intricately painted metal masks which mimicked the skin tone, hair and face shape of wounded soldiers with face disfigurements. ${ }^{29}$ In a 1917 edition of "The Lancet" Derwent Wood describes his process:

My work begins where the work of the surgeon is completed...I endeavor by the means of the skill I happen to possess as a sculptor to make a man's face as near as possible to what it looked like before he was wounded....the patient acquires his old selfrespect, self-assurance, self-reliance and can take pride once more in his personal appearance. $^{30}$

This phrase "can take pride once more" is a key one that is echoed both in the wording of disabled legislature as well as literature by disabled artists. We can see from Derwent Wood's words and in later writings from the $20^{\text {th }}$ and $21^{\text {st }}$ century a push for an advancement of dignity among the disabled that is lacking in previous centuries' contexts.

The overarching theme of the $21^{\text {st }}$ century is best summed up in the words of Vivian Sobchak (an amputee): "Not only do I see myself as fully human, but I also know intimately my prosthetic leg's essential inertia and lack of motivating volition." 31 This sentiment is reaffirmed by Reid Albano, a veteran of the war in Afghanistan, who also is missing a leg: "Though I know full well my false leg is a part of me, I am not defined by my false leg and never will be." 32 This sentiment is in line with a quote by theorist Steven Kurzman (also an amputee): “Artificial limbs do not disrupt amputee's bodies, but rather reinforce our publicly perceived normalcy and humanity." ${ }^{33}$ It is this overarching agency of the individual that resonates from these comments and is something that is missing from the earlier historical narrative. Part of this, however, may be due to a lack of representation, due to many amputees and disabled people being pushed to the margins of society and records of their thoughts and beliefs about their own condition marginalized. Albano further accentuates this increased contemporary narrative of agency in regards to identity and prosthetics:

I'd venture that becoming an amputee has made me vastly more self-confident than I otherwise might be, if for no other reason than the fact that people rarely expect me to be able to perform since I am a cripple, and then are tremendously astonished and impressed that I can basically do everything I did prior to my injury. ${ }^{34}$

When dealing with the phenomenon of the integration of technology and human beings, it is important to define briefly the relevant and poignant theory of "posthumanism". Rosi Braidotti broaches this subject by defining the tragedies that have unfolded since the dawn of the conception of "humanism" as philosophical thought. ${ }^{35}$ She argues that while nominally promoting freedom and equality, humanism has also 'sexualized, racialized and naturalized the 'others' to disposable

\footnotetext{
${ }^{29}$ Figure 7

${ }^{30}$ Derwent Wood, F, The Lancet, 1917, p.949

${ }^{31}$ Sobchak, V, A Leg to Stand on: Prosthetics, Metaphor and Materiality, 2006, p.17

32 Interview with Reid Albano, 2019

${ }^{33}$ Sobchak, 2006

${ }^{34}$ Interview with Reid Albano,2019

${ }^{35}$ Braidotti, The Posthuman,_2011
} 
bodies". ${ }^{36}$ We can read this in the marginalization of the disabled figures mentioned earlier, the cripples of Brueghel, and the broken and disturbed men in the post-World War One world fabric. In a way, these figures help to prove the point that Braidotti is making, showing that these are the casualties of a humanism, which has failed. Braidotti does not want to present this idea as one of "anti-humanism" but rather is interested in exploring alternative conceptualizations of the human body, the human subject and the way they can be interfaced with reality. Raoul Hausmann's aforementioned conception of the machine-melded man written about in Der Aktion, who was in service to the capitalist overlords working twenty-four hours a day, can be read as a twisted approach to the dark side of the posthuman. Instead of liberating itself from the trappings of the capitalist patriarchy of industry, the posthuman falls into its clutches. Jeanine Thewatt-Bates highlights this fact in her book dealing with posthumanity Cyborg Selves: "We must not ignore the possible posthuman representation of an invasion of bodily integrity as well as political exploitation and oppression." 37

Sobchak, who is actually physically affected by the issue of disability and not merely positioned from a theoretical perspective, in some ways fundamentally disagrees with these ideas of posthumanism. She claims it mitigates the independence and agency of the individual body by focusing too much on the thing that propels the individual into posthumanity, in this case the prosthetic device. In an ironic way, by pushing this integration of new modes of being, Sobchak claims a merely theoretical and rhetorical conception posthumanism in some ways removes the agency it aspires to gives, Sobchak writes:

Indeed most of the scholars far too quickly mobilize their fascination with artificial and "posthuman" extensions of "the body" in the service of rhetoric (and in some cases poetics) that is always located elsewhere. ${ }^{38}$

Though not denying the importance of conceptualizing the idea of "posthumanity", Sobchak enforces the belief that the affected and corporeal individual must not be lost to the rhetorical umbrella of the posthuman ideology. In this way she demands that agency be given to the individual, which follows the earlier tenants of Biesalski, as well as the works of Oliveira Barata.

The work of Sophie de Oliveira Barata, the founder of the Alternative Limb Project c. 2009, is perhaps the best example showing how prostheses and disability can be transformed into a mode of personal agency. Her work is a critically important artistic step in the development of prosthetics and deals with these themes of body image and evolution while simultaneously promoting positive conversations around disability and body diversity. Oliveira Barata utilizes innovative technology and her extensive background in film special effects to create individualized prosthetic art works. Oliveira Barata found her work in special effects to be lacking in a sense of personal connection and wished to create something more meaningful. She mentions the specific advancements of technology as a motivating factor: "I saw the incredible advancements that were being made with silicon technology to create realistic skin, as well as things like 3-D printers coming into use. I wanted to utilize these amazing new technologies to create something more meaningful that would help to individually change people's lives. ${ }^{, 39}$

\footnotetext{
${ }^{36}$ Braidotti, 2011,

${ }^{37}$ Thewatt-Bates, Cyborg Selves,_2016, p.3

${ }^{38}$ Sobchak, 2006, p. 20

${ }^{39}$ Interview with Oliveira Barata, 2019
} 
Each one of her works is an unique piece of art that is made in collaboration with a trained prosthetist and the amputee. ${ }^{40}$ Oliveira Barata states: "I want to create pieces that are coming directly from people's souls and directly from their imagination....unless the piece is being worn by the person it was intended for it doesn't mean anything....they create a conversation about the limb and they open up dialogue...instead of seeing what's missing, you see what's there." ${ }^{41}$ This last sentence perhaps best encapsulates this idea of giving agency, by literally describing and talking about what is there in front of you. Oliveira Barata states: "I want to give agency to social interactions, and allowing the amputee to make a statement without a spoken word. The idea is to draw people in, and not just having them stare, but to create a dialogue with the amputee."42

Albano has a similar sentiment about open dialogue being one of the crucial elements to fostering normalcy and autonomy: "I'm always happy to talk about my prosthetic if people are curious, it turns it into something not so alien to people. Most people I have found do not have any negative attitude towards it at all, but merely they are unsure how to broach the subject. ${ }^{43}$

It is through this open discussion with people who have prosthetics that we can more openly understand and perceive this idea of posthumanity. Through these interactions with our technologically altered humans, we can see more clearly how the body and the mind perceives itself reflexively. and through this clearer perception we can better build the global sense of interconnectedness which Braidotti hypothesizes will be a key concept in the dawn of posthumanity. ${ }^{44}$ While Braidotti casts the warning signs that society in the future will deny the body after having denied the soul for so many centuries, the more in-depth look and understanding of those whose bodies have truly been denied, such as Sobchak and Albano, can act as a counteraction to this trend.

The species is entering a new epoch, that of the Anthropocene, and is affecting the world around us and ourselves in unprecedented ways. The position of reimagining and recasting the situation of disabled people is an example of this. The contemporary increase in agency of the disabled shows that subjectivity is rapidly changing, and we must think harder about what the status of a human being means. Posthumanism calls for the need to invent new forms of ethical relations, and through the more complex understanding of those who are affected by the use of prosthetics these relations can be and are being built more strongly.

\footnotetext{
${ }^{40}$ Figure 9

${ }^{41}$ Interview with Oliveira Barata, 2019

${ }^{42}$ Interview with Oliveira Barata, 2019

${ }^{43}$ Interview with Reid Albano, 2019

${ }^{44}$ Braidotti, 2011
} 


\section{Images}

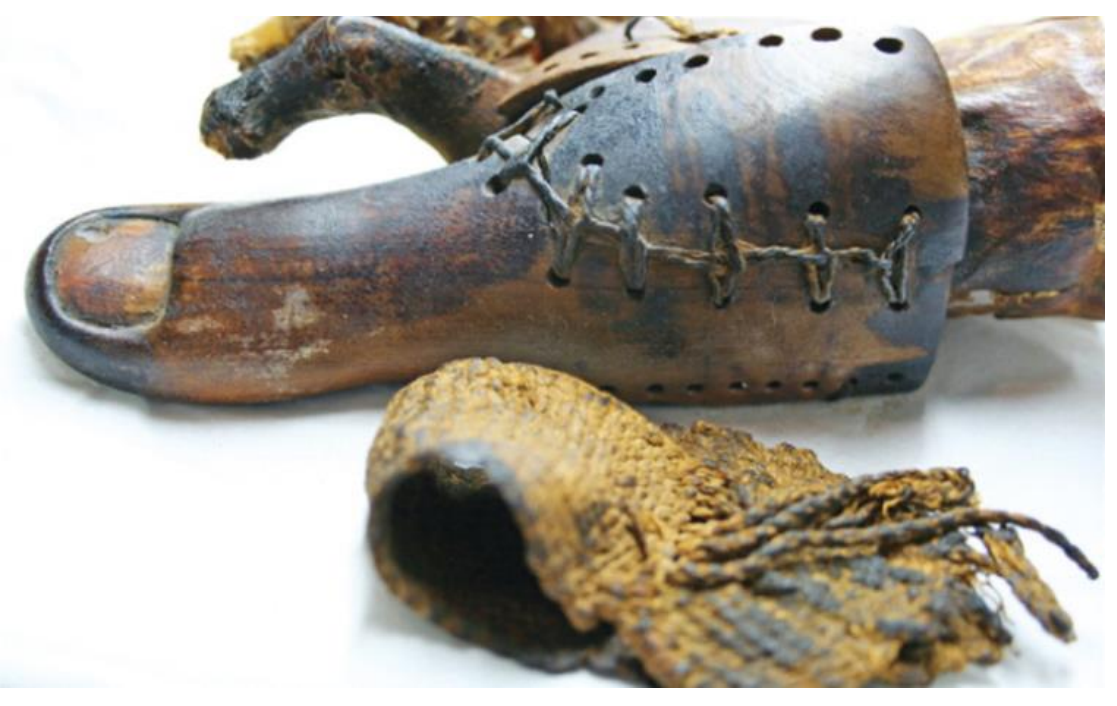

Figure 1. Wooden False Toe, c. 2000 BC, found Luxor Egypt

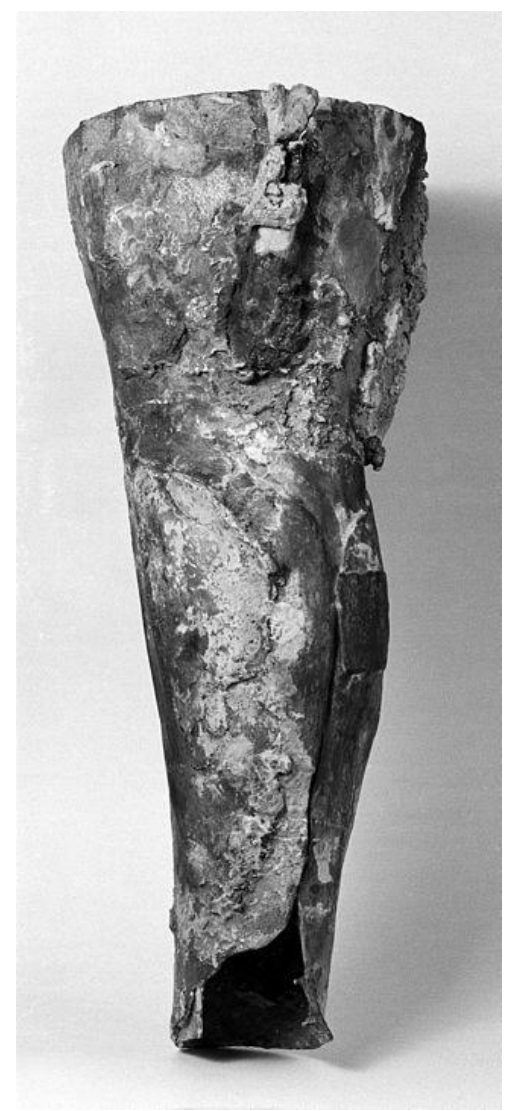

Figure 2. The Capua Leg, 300 BC, Capua Italy 


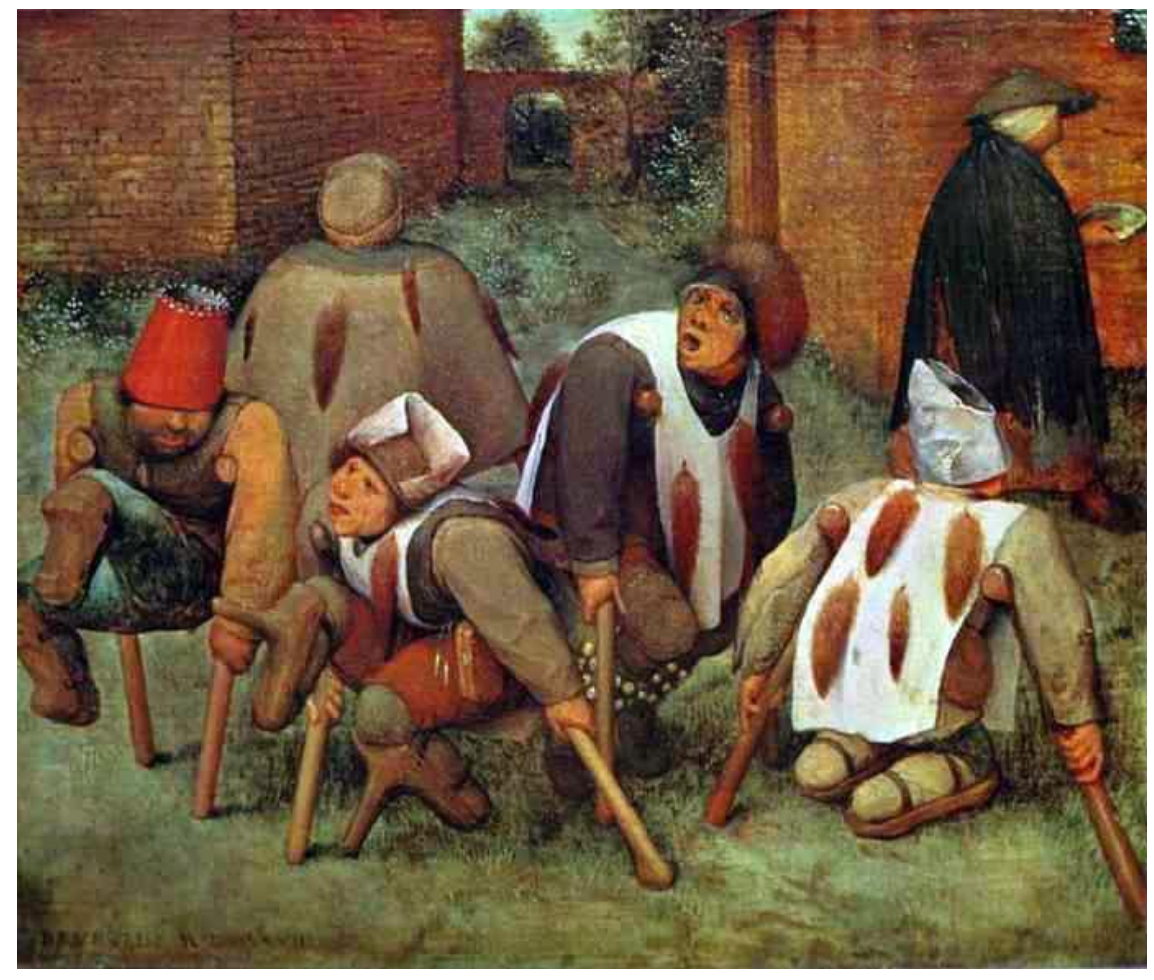

Figure 3. Pieter Brueghel, The Cripples, 1568

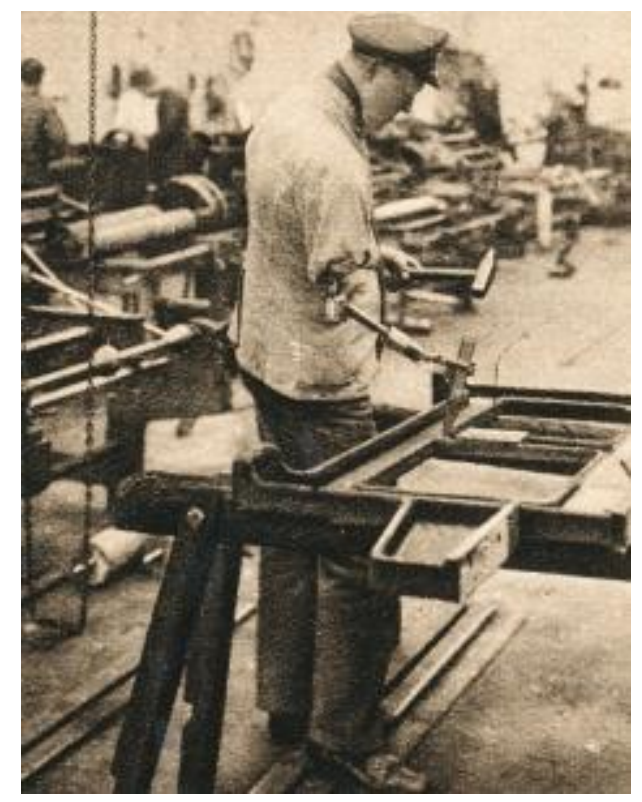

Figure 4. Man with no hands working in a factory, from Konrad Biesalski's, Kriegskrüppelfürsorge: Ein Aufklärungswort zum Troste und zur Hahnung, 1915 


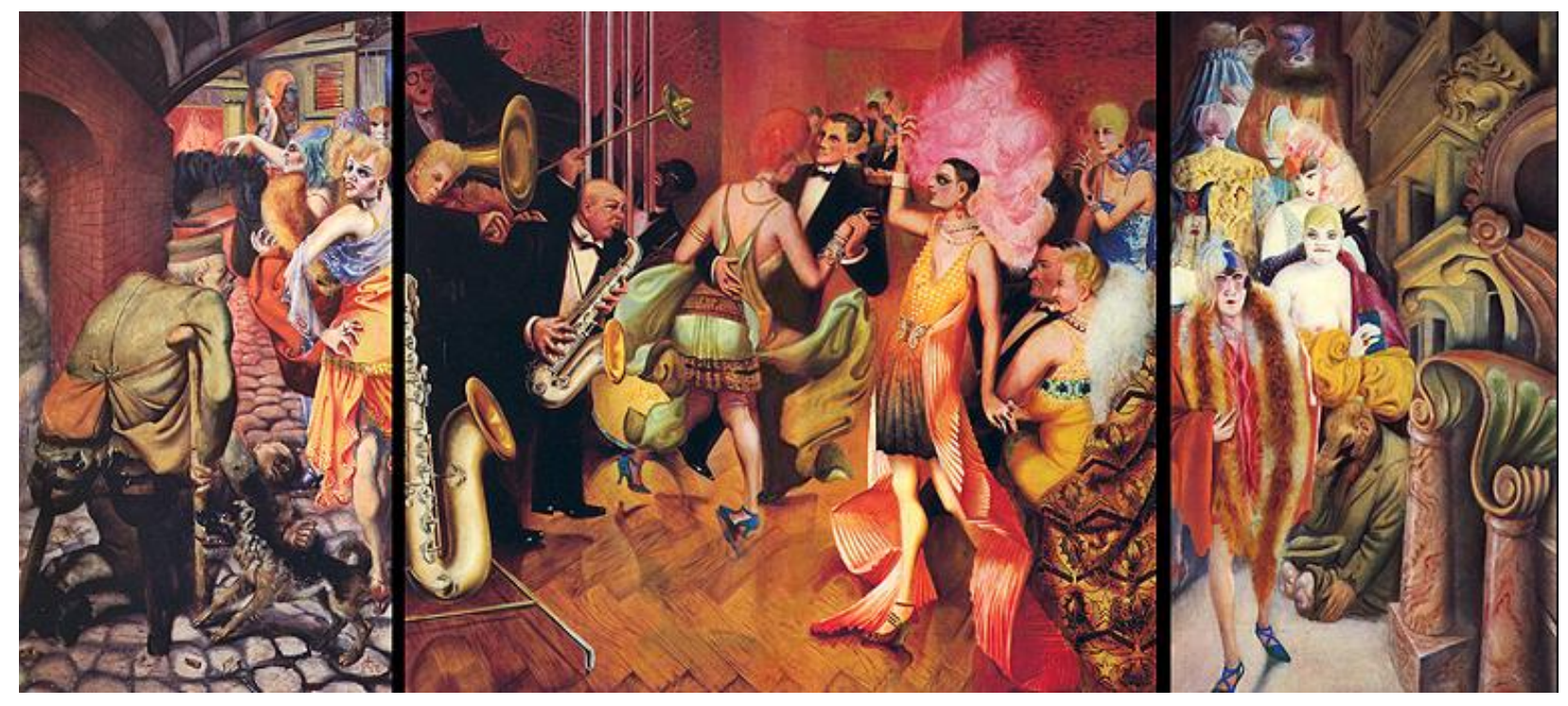

Figure 5. Otto Dix, Metropolis, 1926

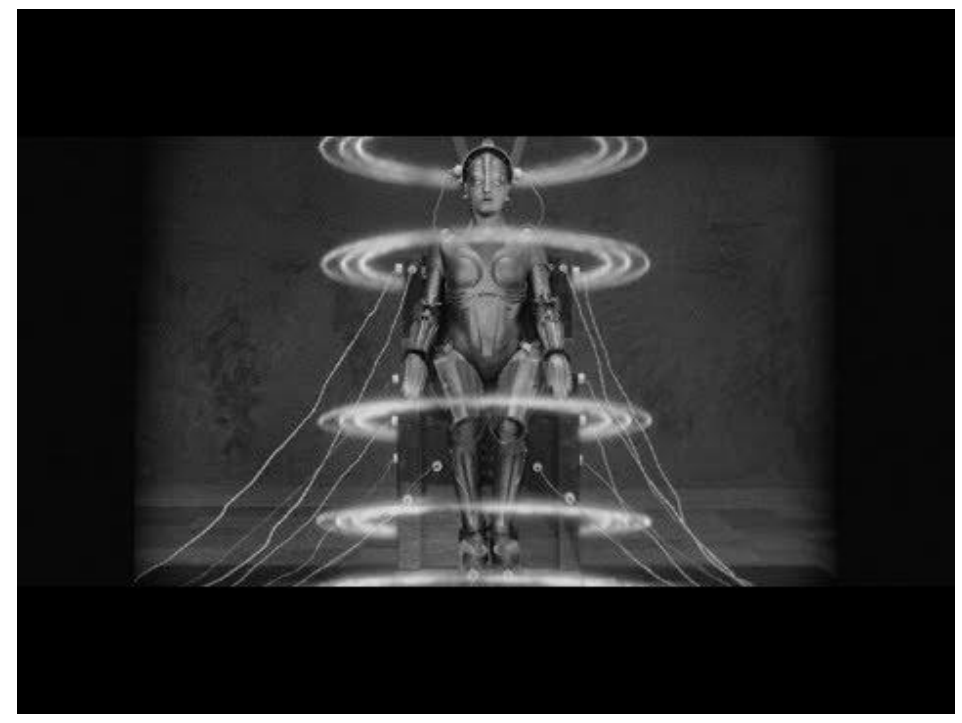

Figure 6. Still from Metropolis, 1927, Fritz Lang

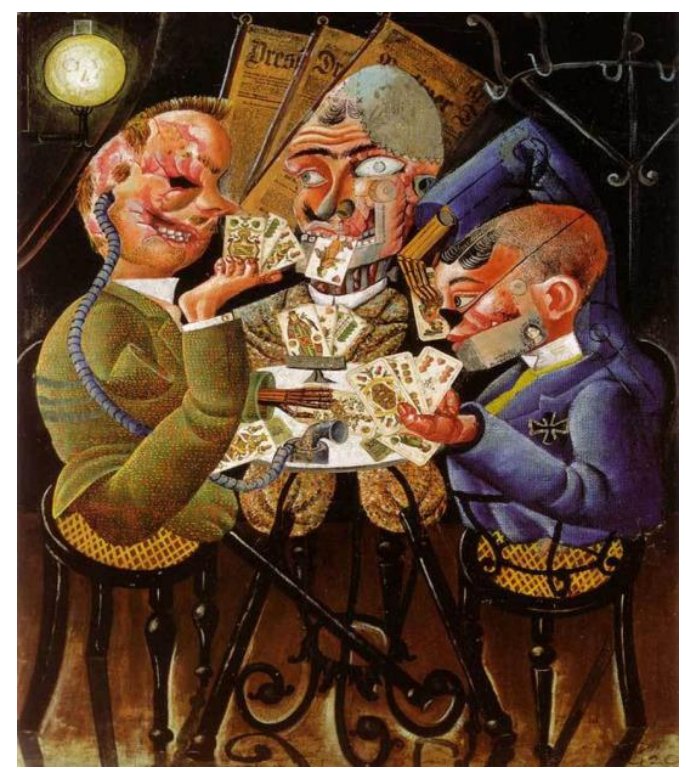

Figure 7. Otto Dix, The Card Players, 1920 


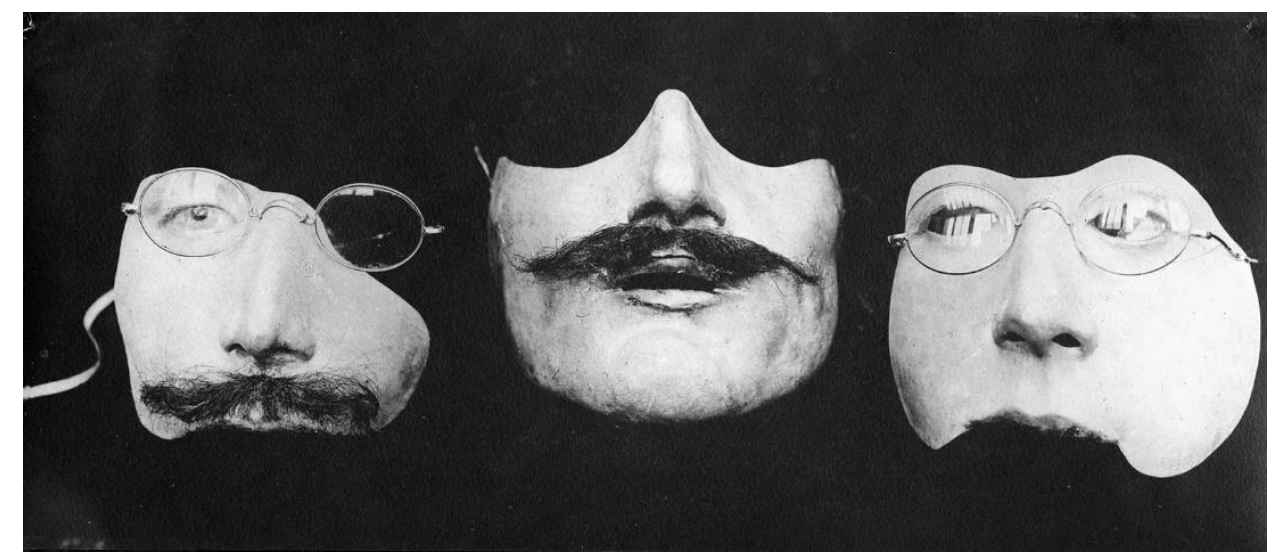

Figure 8. Derwent Wood, Masks, 1919

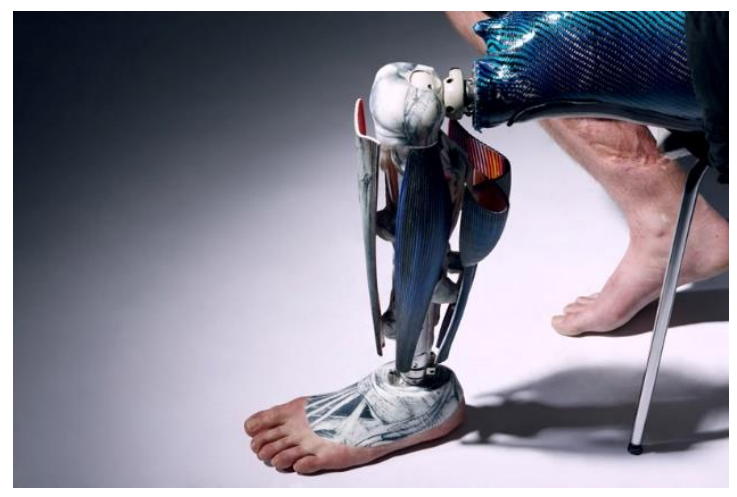

Figure 9. Anatomical Leg, Sophie de Oliveira Barata, 2016

\section{Bibliography}

1. Albano, R, Skype Interview, 2019

2. Andree, C. (2016), "Reproducting Disability and Degeneration in the Victorian Fin de Siècle ", Literature Compass, vo. 13, no. 4, pp. 236-244

3. Braidotti, R. (2013). "The Posthuman", Hoboken, Polity

4. Bliquez, J. (1983), “Classical Prosthetics.” Archaeology, vol. 36, no. 5, pp. 25-29.

5. Clarke, O. (2014). Medical advances from horrors of war. [online] BBC News. Available at: https://www.bbc.co.uk/news/uk-wales-28678392 [Accessed 15 Apr. 2019].

6. Draycott, J. (2017). How the ancients invented prosthetics. [online] The Independent. Available at: https://www.independent.co.uk/life-style/health-and-families/healthy-living/severed-limbs-and-wooden-feethow-the-ancients-invented-prosthetics-a7741996.html [Accessed 11 Apr. 2019].

7. Finch, J. (2011). “The Art of Medicine.” The Lancet, 377, pp.549-550.

8. Hernigou, P.,(2014), "Crutch Art Painting in the Middle Ages as Orthopaedic Heritage”, International Orthopaedics, vo.38, no.7, pp. 1535-1542.

9. Heynen, R. (2015) “Degeneration and Revolution”, New York, Brill

10. Martin, E. (2018). Disability Studies in Art History. [online] The Lantern. Available at: ttp://web.colby.edu/thelantern/2018/04/26/disability-studies-in-art-history/ [Accessed 11 Apr. 2019].

11. Oliveira -Barata, O, Skype Interview, 2019

12. Stainton, T. (2004), "Reason's other: the emergence of the disabled subject in the Northern Renaissance " Disability \& Society", Vol. 19, no. 3, pp. 225-243

13. Thewatt-Bates, J (2016), "Cyborg Selves: A Theological Anthropology of the Posthuman", London, Routledge 